\title{
IMPROVEMENT OF SCIENCE AND TECHNOLOGY THROUGH INTERNET OF THINGS (IOT) FOR SMART HOME APPLICATION TRAINING FOR STUDENTS OF SMK NURUL JADID PROBOLINGGO
}

\author{
PENINGKATAN IPTEK MELALUI PELATIHAN PENERAPAN \\ INTERNET OF THINGS (IOT) UNTUK SMART HOME \\ BAGI SISWA SMK NURUL JADID PROBOLINGGO
}

\author{
Amalia Herlina*1, Ahmad Daviatu Firdausi ${ }^{2}$, Sulhan Maulana Akmal Habibi \\ Virgan Dirgantara ${ }^{2}$ \\ ${ }^{1}$ Program Studi Teknik Elektro, Fakultas Teknik, Universitas Nurul Jadid, Paiton Probolinggo \\ ${ }^{2}$ Mahasiswa KKN Kolaborasi Dosen dan Mahasiswa 2021, Universitas Nurul Jadid, Paiton Probolinggo \\ email:amalia@unuja.ac.id
}

\begin{abstract}
The advancement of science and technology in the era of the Industrial Revolution 4.0 is developing rapidly, including the development of the Internet of Things (IoT) which makes the world smarter. An example of its implementation is the smart home system which offers advantages, so that it is currently being widely socialized in Indonesian society. This training aims to provide solutions to partner problems, namely SMK Nurul Jadid, especially Grade 12 students. There are two main problems with partners that have a high level of urgency to be resolved, namely improving science and technology, and developing 21 st century competence for students. The series of activities carried out included 1) Making IoT learning media for smart home systems, 2) Learning about IoT and smart home systems, 3) Training on making smart home designs, 4) Training on assembling smart home system tools, 5) Training on the use of the Blynk Application for smart home control system 6) Development of 21st century competence (digital era literacy, effective communication, inventive thinking, and high productivity). Activity achievement is measured using the before after test (pre-test and posttest) method. From the increasing number of correct answers in the post-test, it is known that there is an increase in students' understanding of science and technology about IoT for smart home systems. Meanwhile, the achievement of 21 st century competency development is measured by the value of case studies given to students in which the entire group of students achieves the predicate of GOOD. The implementation of all training activities went well. The results of the evaluation questionnaire stated that students felt that this training was very beneficial for improving science and technology and also very beneficial for the development of their competencies. Thus, this series of activities is a solution because it can solve internal problems as well as solutions to external problems of partners.
\end{abstract}

Keywords: BLYNK IoT Platforms, Internet of Thing, Smart Home System, Vocational High School

\begin{abstract}
Abstrak
Kemajuan IPTEK di era Revolusi Industri 4.0 berkembang pesat dan cepat, termasuk perkembangan Internet of Things (IoT) yang membuat dunia lebih pintar. Contoh implementasinya adalah sistem smart home yang menawarkan keunggulan, sehingga saat ini mulai banyak disosialisasikan di masyarakat Indonesia. Pelatihan ini bertujuan untuk memberikan solusi permasalahan mitra yaitu SMK Nurul Jadid khususnya siswa Kelas 12. Terdapat dua permasalahan utama mitra yang memiliki tingkat urgensi tinggi untuk diselesaikan, yaitu peningkatan IPTEK dan pengembangan kompetensi abad 21 bagi siswa. Rangkaian kegiatan yang dilakukan meliputi 1) Pembuatan media pembelajaran IoT untuk sistem smart home, 2) Pembelajaran tentang IoT dan sistem smart home, 3) Pelatihan pembuatan desain smart home, 4) Pelatihan perakitan alat sistem smart home 5) Pelatihan
\end{abstract}


penggunaan Aplikasi Blynk untuk sistem kontrol smart home 6) Pengembangan kompetensi abad 21 (literasi era digital, komunikasi efektif, berpikir inventif dan produktivitas tinggi). Capaian kegiatan diukur menggunakan metode tes before after (pre-test dan post-test). Dari jumlah jawaban benar yang meningkat pada post-test, diketahui adanya peningkatan pemahaman siswa terhadap IPTEK tentang IoT untuk sistem smart home. Sedangkan pencapaian pengembangan kompetensi abad 21 diukur dari nilai studi kasus yang diberikan pada siswa yang mana seluruh kelompok siswa mencapai predikat BAIK. Pelaksanaan seluruh kegiatan pelatihan berlangsung dengan baik. Hasil kuesioner evaluasi menyebutkan, siswa merasakan bahwa pelatihan ini sangat bermanfaat bagi peningkatan IPTEK dan juga sangat bermanfaat bagi pengembangan kompetensi mereka. Dengan demikian, rangkaian kegiatan ini merupakan solusi karena dapat menyelesaikan permasalahan internal sekaligus solusi permasalahan eksternal mitra.

Kata kunci: Aplikasi BLYNK, Internet of Thing, Sekolah Menengah Kejuruan, Smart Home System

\section{PENDAHULUAN}

Internet of Things (IoT) adalah teknologi baru yang membuat dunia kita lebih pintar (Malche \& Maheshwary, 2017). IoT memungkinkan pengguna melakukan pengontrolan terhadap seluruh perangkat yang ada di sekitarnya dari jarak jauh dengan menggunakan internet (Junaidi, 2015). Teknologi IoT saat ini telah digunakan untuk menjalankan aktivitas dan menjadi bagian dari kehidupan masyarakat di berbagai bidang. Salah satu contoh implementasi IoT dalam kehidupan masyarakat, adalah sistem rumah pintar/ cerdas (sistem smart home). Implementasi sistem ini bertujuan untuk meningkatkan efisiensi, kenyamanan dan kemudahan dalam sebuah friendly living environment yang membawa manfaat bagi pemilik rumah (Li et al., 2018). Sebuah sistem smart home memungkinkan pengguna dapat melakukan monitoring terhadap semua peralatan rumah, yang bekerja secara otomatis mulai dari pengoperasian pintu gerbang, pencahayaan dari lampu, sampai pada pemantauan level air (R. Hafid Hardyanto, 2017). Keunggulan tersebut menjadi daya tarik kuat dan menjadi alasan utama mengapa sistem smart home saat ini mulai banyak disosialisasikan di masyarakat Indonesia.

Implementasi IoT untuk sistem smart home juga menjadi topik bahasan dalam berbagai penelitian untuk pengembangan sistem tersebut. Sebagai contoh adalah hasil penelitian tentang rancang bangun Smart Home, Smart Control berbasis Bluetooth Mikrokontroler, yang telah dilakukan oleh B. Adi Jaya dan A. Herlina (2019). Dengan alat yang dibangun dari penelitian tersebut, pemilik rumah dapat menyalakan dan mematikan (on/off) lampu rumah secara otomatis dan mudah, menggunakan smart phone android yang terkoneksi dengan Mikrokontroler Arduino melalui Bluetooth (Adi \& Herlina, 2019).

Selanjutnya, dalam penelitian yang dilakukan oleh Setiyani et.al (2019) sistem smart home diimplementasikan di sektor bidang perumahan sehingga menjadi keunggulan kompetitif bagi pengembang perumahan (Setiyani, 2019). Sistem yang dibangun menggunakan Raspberry PI berbasis android. Raspberry Pi memiliki spesifikasi hardware yang lebih bagus dibandingkan Arduino. Lebih lanjut, perkembangan implementasi IoT tidak hanya sebatas pada smart home, melainkan untuk sistem kota pintar/cerdas (smart city) pada penelitian yang dilakukan oleh Subani et.al (2021). Penelitian ini membahas tentang IoT dan instalasi komputer pada perkembangan sebuah smart city, yaitu ibukota DKI Jakarta (Subani et al., 2021). 
Uraian di atas menggambarkan bahwa kemajuan ilmu pengetahuan dan teknologi (IPTEK) di era revolusi industri 4.0 berkembang begitu pesat dan cepat, termasuk perkembangan IoT. Kecanggihan teknologi terlihat seperti saling berlomba untuk mewujudkan perkembangannya. Untuk itu, individu perlu kecerdasan diri agar dapat mengikuti arus dan memanfaatkan segala kecanggihan yang ada sehingga dapat menjadi alternatif pilihan untuk mengembangkan kemampuan maupun untuk bisnis (Subani et al., 2021).

Kegiatan Peningkatan IPTEK Melalui Pelatihan Penerapan Internet of Things (IoT) untuk Smart Home Bagi Siswa SMK Nurul Jadid Paiton Probolinggo, merupakan kegiatan pengabdian kepada masyarakat (PKM) yang dilakukan oleh Tim Pelaksana PKM dari Program Studi Teknik Elektro Universitas Nurul Jadid (UNUJA) Paiton Probolinggo. Kegiatan pengabdian ini bermitra dengan Sekolah Menengah Kejuruan Nurul Jadid (SMKNJ) Paiton Probolinggo. Pelatihan ini ditujukan untuk siswa SMKNJ kelas 12, yang merupakan calon lulusan pada tahun 2021.

Berdasarkan analisa situasi yang dilakukan Tim Pelaksana PKM pada mitra, permasalahan utama yang dihadapi mitra adalah tingkat pengetahuan dan pemahaman siswa SMKNJ tentang IoT dan implementasinya yang masih rendah, khususnya untuk membangun sistem smart home. Kondisi ini terjadi akibat pembelajaran tentang IoT masih kurang maksimal karena tidak diberikan dalam sebuah mata pelajaran khusus, melainkan menjadi bagian dari mata pelajaran Fisika, sub topik bahasan tentang Elektronika. Akibatnya, terjadi kendala dalam proses pembelajaran topik ini, terlebih pada praktik rancang bangun sistem smart home baik alat maupun sistem kontrol.

Sesuai dengan amanat Undang-Undang Nomor 20 Tahun 2003 tentang Sistem Pendidikan Nasional, Sekolah Menengah Kejuruan (SMK) merupakan lembaga pendidikan yang bertujuan mencetak lulusan yang memiliki keterampilan untuk mampu menangani suatu pekerjaan tertentu (Sajidan et.al, 2018). Menjawab amanat tersebut, upaya yang dapat dilakukan oleh mitra adalah melakukan upaya peningkatan IPTEK, salah satunya adalah pengetahuan tentang IoT dan implementasinya untuk membangun sistem smart home yang sedang menjadi tren perkembangan teknologi. SMKNJ juga berkewajiban membekali siswanya agar siap masuk dalam bursa kerja. Untuk itu, pembelajaran di SMKNJ harus disusun dan dilakukan sedemikian rupa sehingga mampu memunculkan indikator-indikator kompetensi siswa dalam pembelajaran abad 21. S. Afandi (2017) menyebutkan bahwa dalam konteks membekali lulusan SMK agar siap masuk dalam bursa kerja, terdapat indikator-indikator kompetensi dalam pembelajaran abad 21 yang perlu dimunculkan yaitu: 1) literasi era digital (digital age literacy), 2) komunikasi efektif (effective communication), 3) berpikir inventif (inventive thinking) dan 4) produktivitas tinggi (high productivity) (Afandi, 2017).

Untuk memenuhi harapan dan kebutuhan di atas, saat ini mitra mengalami masalah pada tingkat literasi era digital pada siswa. Berdasarkan hasil observasi sederhana yang dilakukan oleh pihak sekolah pada siswa SMKNJ kelas 12, tingkat literasi era digital masih rendah. Salah satu indikatornya yaitu kendala pada kemampuan dan kemandirian siswa beradaptasi terhadap model pembelajaran E-learning selama masa pandemi Covid 19. Akibatnya, proses transfer ilmu tidak dapat dilakukan secara maksimal seperti saat berlangsungnya pembelajaran tatap muka (luring), termasuk pembelajaran tentang IoT dan praktik rancang bangun sistem smart home

Permasalahan yang telah diuraikan di atas, oleh mitra dikategorikan sebagai permasalahan internal. Mitra mengharapkan adanya solusi untuk permasalahan internal tersebut, sehingga permasalahan eksternal yaitu tuntutan pada era revolusi industri 4.0 
dan juga tuntutan dari dunia kerja secara langsung juga dapat diselesaikan. Kedua permasalahan ini mempunyai tingkat urgensi yang tinggi untuk diselesaikan. Keinginan mitra, siswa lulusan SMKNJ harus dipersiapkan agar memiliki kemampuan kognitif, afektif dan psikomotorik yang baik. Kemampuan kognitif khususnya berfokus pada pembelajaran tentang IoT dan praktik rancang bangun alat sistem smart home. Sedangkan kemampuan afektif dan psikomotorik yang baik, khususnya berfokus pada pengembangan kompetensi yang terkait dengan indikator kompetensi di era revolusi industri 4.0 yaitu tingkat literasi era digital (digital age literacy), kemampuan komunikasi efektif (effective communication), kemampuan berpikir inventif (inventive thinking) dan produktivitas tinggi (high productivity).

Berdasarkan uraian permasalahan di atas, solusi yang ditawarkan Tim Pelaksana PKM yaitu siswa SMKNJ diberikan pembelajaran dan pelatihan tentang penerapan IoT khususnya cara membangun smart home. Secara umum, tujuan kegiatan ini adalah untuk memberikan upaya peningkatan IPTEK dan pengembangan kompetensi kepada siswa. Memperhatikan kondisi dan kemampuan siswa SMKNJ, untuk rancang bangun sistem kontrol smart home dipilih aplikasi Blynk karena merupakan teknologi baru dan mudah untuk digunakan. Tercapainya tujuan pelatihan ini akan menjadi solusi untuk menyelesaikan permasalahan mitra sekaligus sebagai jawaban atas harapan dan keinginan mitra dalam upaya untuk membekali calon lulusannya agar menguasai teknologi terbaru dan siap masuk dalam bursa kerja.

Berdasarkan analisa situasi, mitra membutuhkan kegiatan Peningkatan IPTEK Melalui Pelatihan Penerapan Internet of Things (IoT) pada Sistem Smart Home Bagi Siswa SMK Nurul Jadid Paiton Probolinggo. Selanjutnya dari hasil identifikasi masalah, Tim Pelaksana PKM merumuskan beberapa permasalahan yang membutuhkan solusi yaitu 1) Peningkatan penguasaan IPTEK terbaru. Solusinya dengan memberikan wawasan dan pengetahuan kepada siswa SMKNJ untuk menerapkan IoT khususnya untuk membangun sistem smart home yang dilakukan dengan cara melakukan pembelajaran dan praktik perakitan alat dan juga pemrograman sistem kontrol dengan Aplikasi Blynk, 2) Peningkatan dan pengembangan kompetensi abad 21 bagi siswa. Solusinya adalah memberikan wawasan dan pemahaman kepada siswa meliputi literasi era digital, kemampuan komunikasi efektif, kemampuan berpikir inventif dan kemampuan berproduktivitas tinggi.

\section{METODE PENGABDIAN MASYARAKAT}

Pelaksanaan kegiatan Melalui Peningkatan IPTEK Pelatihan Penerapan Internet of Things (IoT) pada Smart Home Bagi Siswa SMK Nurul Jadid Paiton Probolinggo, dimulai dengan kegiatan pertemuan antara Tim Pelaksana PKM dan Mitra yang dihadiri Kepala Sekolah SMKNJ dan wakil, serta guru pengampu mata pelajaran Fisika untuk mengidentifikasi permasalahan yang secara umum telah disampaikan oleh pihak sekolah. Selanjutnya berdasarkan analisa situasi dan identifikasi permasalahan, Tim Pelaksana PKM menawarkan solusi untuk penyelesaian masalah. Solusi yang ditawarkan tersebut dikemas dalam kegiatan pelatihan yang diberikan untuk siswa SMKNJ kelas 12 yang merupakan calon lulusan tahun 2021. Sebanyak 16 orang siswa mengikuti pelatihan ini. Pelaksanaan pelatihan dilakukan secara luring dengan memberikan jam tambahan pada pelajaran Fisika yang di atur dengan baik sehingga siswa dan guru mata pelajaran tidak merasa terbebani. Kegiatan luring di atur sedemikian rupa dan dilakukan dengan tetap memperhatikan protokol kesehatan pencegahan penularan Covid-19. 
Pada tahap awal pelaksanaan kegiatan ini Tim Pelaksana PKM bekerja sama dengan guru pengampu mata pelajaran Fisika untuk penyusunan rencana kegiatan meliputi jadwal pembelajaran dan pelatihan, pemilihan materi IoT dan pemanfaatannya untuk sistem smart home (teori dan praktik), serta materi untuk pengembangan kompetensi siswa meliputi literasi era digital, kemampuan komunikasi efektif, kemampuan berpikir inventif dan kemampuan berproduktivitas tinggi. Selain itu juga dirancang media pembelajaran meliputi modul pembelajaran dan alat peraga IoT untuk sistem smart home menggunakan aplikasi Blynk. Tim Pelaksana PKM juga membuat video pembelajaran yang dapat membantu siswa dalam proses belajar rancang bangun smart home secara mandiri. Selanjutnya, pelaksanaan kegiatan ini dilakukan oleh Tim Pelaksana PKM yang terdiri dari Ketua Tim dan Anggota Pelaksana PKM yang merupakan mahasiswa Prodi Teknik Elektro semester empat yang sedang mengikuti program KKN.

Metode yang digunakan dalam kegiatan pelatihan ini meliputi pembelajaran luring, pelatihan, dan pendampingan dalam praktik rancang bangun smart home. Pelaksanaan seluruh kegiatan memerlukan waktu kurang lebih dua bulan. Sedangkan alur pelaksanaan kegiatan pelatihan ditampilkan pada Gambar 1 di bawah ini:

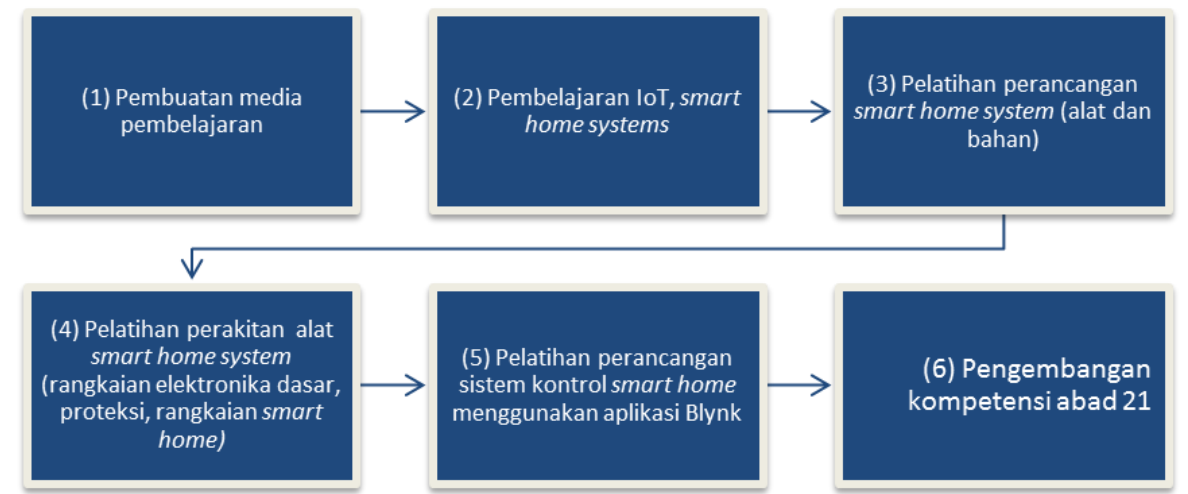

Gambar 1. Alur Pelaksanaan Kegiatan Pokok

Masing-masing kegiatan tersebut mempunyai indikator capaian yang berbeda. Indikator capaian untuk masing-masing kegiatan dapat dilihat pada Tabel 1:

\section{Tabel 1. Kegiatan dan Indikator Capaian}

\begin{tabular}{cll}
\hline No. & \multicolumn{1}{c}{ Kegiatan } & \multicolumn{1}{c}{ Indikator Capaian } \\
\hline 1. & $\begin{array}{l}\text { Pembuatan media } \\
\text { pembelajaran IoT untuk sistem } \\
\text { smart home (teori dan } \\
\text { praktik) }\end{array}$ & $\begin{array}{l}\text { Tersedia modul pembelajaran, alat peraga } \\
\text { dan video pembelajaran yang sesuai dengan } \\
\text { kebutuhan siswa SMKNJ }\end{array}$ \\
\hline 2. & $\begin{array}{l}\text { Pembelajaran tentang IoT, } \\
\text { sistem smart home }\end{array}$ & $\begin{array}{l}\text { Siswa memahami materi pembelajaran } \\
\text { tentang IoT, sistem smart home }\end{array}$ \\
\hline 3. & $\begin{array}{l}\text { Pelatihan perancangan sistem } \\
\text { smart home (alat dan bahan) }\end{array}$ & $\begin{array}{l}\text { Siswa memahami dan menerapkan hasil } \\
\text { pelatihan perancangan sistem smart home } \\
\text { (alat dan bahan) }\end{array}$ \\
\hline 4. & $\begin{array}{l}\text { Pelatihan perakitan alat sistem } \\
\text { smart home (rangkaian } \\
\text { elektronika dasar, proteksi, } \\
\text { rangkaian smart home) }\end{array}$ & $\begin{array}{l}\text { Siswa memahami dan menerapkan hasil } \\
\text { pelatihan perakitan alat sistem smart home } \\
\text { (rangkaian elektronika dasar, proteksi, } \\
\text { rangkaian smart home) }\end{array}$ \\
\hline
\end{tabular}




\begin{tabular}{rll}
\hline No. & \multicolumn{1}{c}{ Kegiatan } & \multicolumn{1}{c}{ Indikator Capaian } \\
\hline 5. & $\begin{array}{l}\text { Pelatihan perancangan sistem } \\
\text { kontrol smart home } \\
\text { menggunakan aplikasi Blynk }\end{array}$ & $\begin{array}{l}\text { Siswa mampu memahami dan menerapkan } \\
\text { hasil pelatihan perancangan sistem kontrol } \\
\text { smart home menggunakan aplikasi Blynk }\end{array}$ \\
\hline 6. & $\begin{array}{l}\text { Pengembangan kompetensi } \\
\text { abad 21 (literasi era digital, } \\
\text { komunikasi efektif, berpikir } \\
\text { inventif dan produktivitas } \\
\text { tinggi) }\end{array}$ & $\begin{array}{l}\text { Siswa memahami dan menerapkan hasil } \\
\text { pembinaan kompetensi (literasi era digital, } \\
\text { komunikasi efektif, berpikir inventif dan } \\
\text { produktivitas tinggi) }\end{array}$ \\
\hline
\end{tabular}

Untuk mengukur capaian upaya peningkatan IPTEK maka siswa peserta pelatihan harus mengikuti pre-test dan post-test tentang IoT dan smart home. Sedangkan untuk mengukur pengembangan kompetensi abad 2 siswa, dinilai dari jawaban pada studi kasus yang diberikan. Hasil dari tes ini menjadi indikator keberhasilan dan merupakan bahan evaluasi dalam pelaksanaan pelatihan. Pelaksanaan tes diperlukan karena tes ini merupakan penilaian dengan pendekatan otentik yang dimaksudkan untuk dapat mengukur secara signifikan hasil belajar peserta didik pada aspek sikap, keterampilan, dan pengetahuan. Signifikan yang dimaksud dalam konteks ini adalah penilaian dilakukan secara komprehensif, sehingga diperoleh informasi yang lengkap mengenai kemajuan belajar peserta didik (Sajidan et.al, 2018).

\section{HASIL DAN PEMBAHASAN}

Solusi yang ditawarkan Tim Pelaksana PKM untuk mitra, direalisasikan melalui pelaksanaan rangkaian kegiatan pelatihan. Berikut ini adalah kegiatan yang telah dilakukan dan hasilnya:

\section{Pembuatan Media Pembelajaran IoT untuk Sistem Smart Home}

Media pembelajaran yang dibuat menyesuaikan dengan kebutuhan, kondisi serta kemampuan siswa sekolah mitra. Terdapat tiga macam media pembelajaran yang dibuat untuk pelatihan ini. Media tersebut adalah 1) Modul Pembelajaran, 2) Alat Peraga dan 3) Video Pembelajaran.

Pertama, Modul Pembelajaran

Terbagi menjadi tiga modul yang berbeda, agar pembelajaran untuk masingmasing topik dapat lebih fokus. Modul pembelajaran yang dibuat yaitu 1) Modul pertama: Konsep IoT dan sistem smart home. Berisi materi tentang teori dan konsep IoT dan sistem smart home. Modul ini juga berisi penjelasan tentang tujuan dan manfaat, ragam contoh implementasi IoT dan sistem smart home. 2) Modul kedua: Panduan Praktik Penggunaan IoT untuk sistem smart home. Berisi tentang materi pembelajaran yang digunakan saat melakukan praktik perancangan, perakitan alat smart home serta penggunaan aplikasi Blynk untuk perancangan sistem kontrol smart home. 3) Modul Ketiga: Pengembangan Kompetensi Abad 21. Berisi materi tentang literasi era digital, cara melakukan komunikasi efektif, berpikir inventif dan produktivitas tinggi.

Kedua, Alat Peraga.

Alat peraga yang dibuat merupakan bentuk visualisasi rancangan sistem smart home dan digunakan selama pembelajaran. Alat peraga ini dibuat sesuai dengan rancangan elektronik dan kontrol sistem smart home sederhana yang harus dipahami siswa. Dengan alat peraga ini, siswa dapat melihat kondisi riil alat sistem smart home 
yang mana teori dan konsepnya dapat dipelajari pada modul pembelajaran pertama dan kedua. Alat peraga ditampilkan pada Gambar 2 berikut ini:

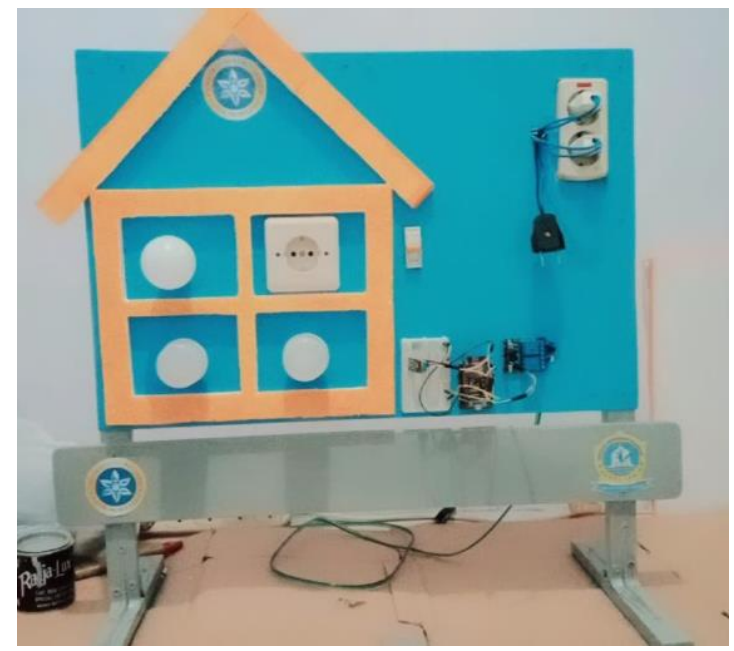

Gambar 2. Alat Peraga Pembelajaran IoT untuk Sistem Smart Home

Ketiga, Video Tutorial.

Video Tutorial berdurasi selama \pm 10 menit, berisi panduan pembuatan smart home. Di dalamnya berisi langkah-langkah dan penjelasan yang gamblang mulai dari cara merancang sampai dengan membangun alat dan kontrol pada smart home. Penjelasan disampaikan dengan jelas dan padat, menggunakan bahasa yang mudah dipahami oleh siswa dan tidak membosankan. Dengan demikian, siswa dapat belajar secara mandiri kapan pun dan dimanapun dengan cara mengulangi pembelajaran di sekolah dengan bantuan video tutorial. Video tutorial ini diunggah ke channel You Tube sehingga memudahkan akses siswa untuk memanfaatkan video tutorial selama $24 / 7$.

\section{Program Pembelajaran Penerapan IoT untuk Sistem Smart Home}

Kegiatan pelatihan ini dimulai dengan kegiatan pembelajaran yang mengacu pada materi pada Modul Pertama yang berisi pengenalan konsep IoT dan sistem smart home. Pada program ini, siswa diberi pengetahuan tentang definisi IoT dan sistem smart home beserta manfaat dan keuntungan penggunaannya. Siswa juga dikenalkan dengan contohcontoh implementasinya seperti termostat dan humidity sensor (alat yang bisa digunakan untuk memantau suhu dan kelembapan di ruangan yang dapat dipantau dimana saja dan kapan saja), lampu dan AC yang bisa dinyalakan ataupun dimatikan hanya dari smart phone dan magnetic door sensor (alat yang akan mengirim peringatan jika alarm aktif dan pintu terbuka). Foto kegiatan pembelajaran ditampilkan pada Gambar 3 di bawah ini: 

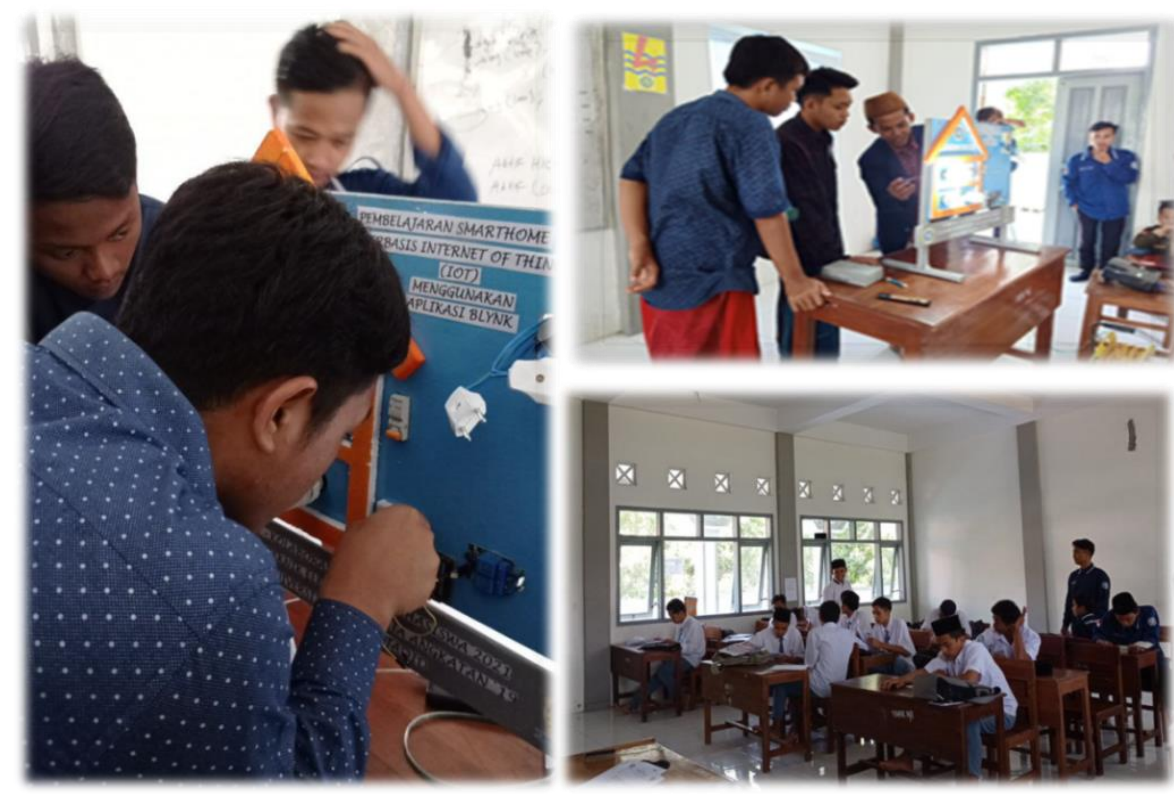

Gambar 3. Kegiatan Program Pembelajaran Bagi Siswa SMKNJ

Dalam program pembelajaran ini siswa juga dikenalkan dengan komponenkomponen untuk membuat alat smart home, antara lain Nodemcu ESP8266, Relay, Sensor DHT11, Breadboard, Miniature Circuit Breaker (MCB). Untuk membuat sistem kontrol smart home siswa dikenalkan untuk menggunakan Aplikasi Blynk . Video tutorial juga digunakan sebagai media pembelajaran untuk memberi gambaran yang lebih jelas pada siswa tentang materi yang disampaikan oleh Tim Pelaksana PKM

\section{Pelatihan Perancangan Sistem Smart Home}

Pelatihan perancangan sistem smart home mengacu pada materi pembelajaran di Modul Kedua. Video tutorial juga digunakan sebagai media pembelajaran untuk memberi gambaran yang lebih jelas pada siswa tentang materi yang disampaikan oleh Tim Pelaksanaan PKM. Kegiatan di awali dengan pengenalan cara kerja smart home. Selanjutnya siswa diberi pengetahuan serta dilatih untuk membuat perancangan alat, menggambar desain dan skematik rangkaian smart home. Berikut ini contoh gambar skematik rangkaian smart home yang dihasilkan oleh siswa SMKNJ.

\section{Pelatihan Perakitan Alat Smart Home}

Sesi pelatihan di bagian ini mengacu pada materi pembelajaran di Modul Kedua. Melalui kegiatan ini siswa SMKNJ melakukan praktik langsung cara merakit alat dan pada smart home, termasuk melakukan perancangan sistem kontrol smart home menggunakan Aplikasi Blynk. Dengan demikian, siswa semakin mengetahui fungsi dan cara kerja masing-masing komponen-komponen yang digunakan untuk smart home. Video tutorial juga digunakan sebagai media pembelajaran untuk memberi gambaran yang lebih jelas pada siswa tentang materi yang disampaikan oleh Tim Pelaksanaan PKM. Hasil karya praktik siswa SMKNJ yang mereplika dari Alat Peraga dapat dilihat pada Gambar 4: 


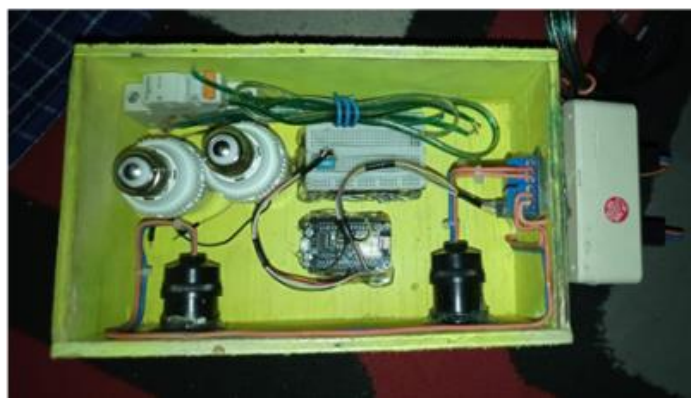

Gambar 4. Rangkaian Sistem Smart Home Karya Siswa SMKNJ

Materi yang diberikan dapat dipahami dengan baik oleh siswa dalam waktu yang singkat. Siswa SMKNJ dapat mengikuti pelatihan penggunaan aplikasi ini dengan baik. Berikut ini adalah code sketch yang diajarkan pada siswa SMKNJ. Selanjutnya siswa berlatih dan berkreasi untuk membuat antarmuka grafis untuk proyek yang akan diimplementasikan hanya dengan metode drag and drop widget.

\section{Pengembangan Kompetensi Abad 21}

Materi pengembangan kompetensi ini diberikan setelah pembelajaran dan seluruh rangkaian pelatihan smart home termasuk sistem kontrolnya selesai dilakukan. Materi yang diberikan mengacu pada Modul Ketiga. Secara umum, tujuan kegiatan ini siswa mempunyai self motivation untuk menjadi manusia pembelajar agar siap menghadapi segala tantangan di era revolusi 4.0. Hasil dari kegiatan ini, literasi era digital meningkat, mampu berkomunikasi efektif, mampu berpikir inventif dan mampu berproduktivitas tinggi.

Materi disampaikan dengan memanfaatkan video-video berisi wawasan dan motivasi yang diperoleh dari internet, yang terkait dengan topik pengembangan kompetensi di atas. Sebagai feed back-nya siswa aktif untuk mencari video dan sumber belajar digital yang terkait dengan topik IoT dan sistem smart home. Seluruh hasil pencarian video dan sumber belajar disebut diunggah siswa pada Google Classroom yang disediakan Tim Pelaksanaan PKM. Dari kegiatan ini, sekaligus literasi era digital siswa dapat ditingkatkan. Selanjutnya dilakukan diskusi dan pembahasan tentang topiktopik pada video dan sumber belajar digital yang telah terkumpul. Siswa SMKNJ didorong agar aktif untuk bertanya, menuliskan pendapat lalu menyampaikan pendapat tersebut di depan kelas secara bergiliran. Siswa juga diberi kesempatan untuk memimpin diskusi dan menjawab pertanyaan dari siswa lain, sehingga siswa dapat melatih kemampuan berkomunikasi efektif.

Peningkatan dan kemampuan berpikir inventif dan produktivitas tinggi dilakukan dengan cara memberikan studi kasus sederhana pada siswa SMKNJ. Siswa dibagi menjadi 4 kelompok, masing-masing kelompok terdiri dari 4 siswa. Melalui kegiatan ini, siswa tertantang berpikir "out of the box" untuk menyelesaikan masalah pada kasuskasus tersebut sehingga diketahui tingkat kreativitas dan produktivitasnya.

\section{Pengukuran dan Evaluasi}

Kegiatan pengukuran digunakan untuk mengukur sejauh mana penerapan dan pelaksanaan rangkaian kegiatan PKM yang dilakukan telah tepat sasaran. Pengukuran peningkatan IPTEK dilakukan dengan melakukan metode tes before after yang terdiri dari pre-test dan post-test . Pelaksanaan kegiatan pre-test diberikan pada siswa sebelum siswa diberikan materi apapun tentang IoT dan sistem smart home. Selanjutnya, setelah 
seluruh rangkaian kegiatan pelatihan selesai dilakukan, siswa diberikan post-test. Soal yang diberikan untuk post-test sama dengan soal pre-test. Dari pelaksanaan tes ini dapat diketahui kemajuan pemahaman siswa terhadap IPTEK dari rangkaian kegiatan pelatihan yang telah diikuti. Sedangkan pengukuran pencapaian pengembangan kompetensi abad 21 diukur dari nilai dari studi kasus yang diberikan pada siswa. Bentuk soal tes yang diberikan pada siswa adalah pilihan ganda yang seluruhnya berjumlah 20 soal yang harus dijawab oleh siswa.

Materi dalam soal tersebut mewakili 4 kelompok topik yang harus dipahami siswa yaitu Konsep IoT, Konsep sistem smart home, Komponen alat smart home, Aplikasi Blynk. Gambar 5 di bawah ini adalah grafik peningkatan pemahaman siswa terhadap masing-masing topik yang disimpulkan dari peningkatan jumlah jawaban benar pada pre-test dan post-test: Jawaban yang diberikan siswa menggambarkan tingkat pemahamannya.

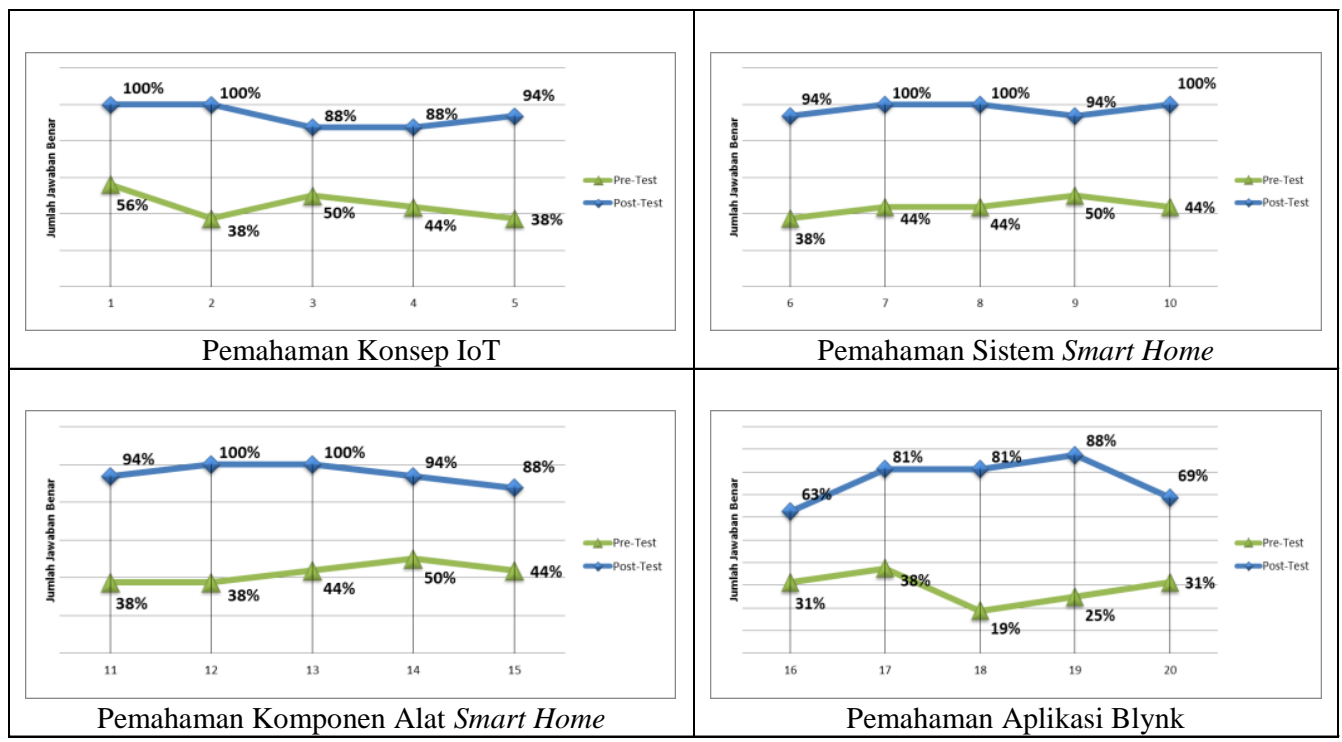

Gambar 5. Grafik Peningkatan Pemahaman Siswa Terhadap 4 Topik Pembelajaran

Jika dihitung rata-ratanya, dapat diketahui terjadi peningkatan jumlah jawaban benar untuk masing-masing topik pada hasil post-test. Grafik 1 di bawah ini adalah grafik rata-rata jumlah jawaban benar per topik (pada pre-test dan post-test):

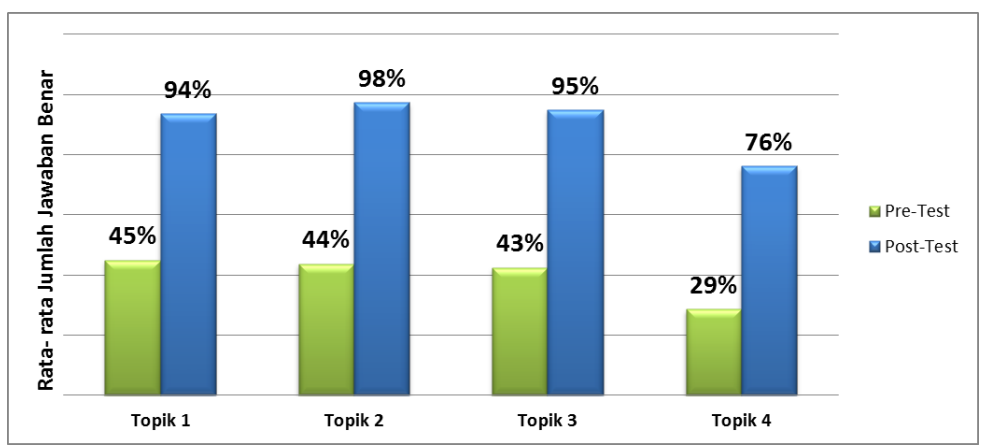

Grafik 1. Rata-Rata Jumlah Jawaban Benar per Topik 
Capaian pengembangan kompetensi abad 21 tergambar dari skor rerata hasil studi kasus yang dilakukan siswa. Rekap nilai pengembangan kompetensi untuk masing-masing kelompok ditampilkan pada Tabel 2 di bawah ini:

\section{Tabel 2 Rekap Nilai Studi Kasus Siswa SMKNJ}

\begin{tabular}{lcccc}
\hline \multicolumn{1}{c}{ Kemampuan } & Kelompok 1 & Kelompok 2 & Kelompok 3 & Kelompok 4 \\
\hline Literasi era digital & 83 & 85 & 85 & 87 \\
\hline Komunikasi efektif & 75 & 75 & 79 & 83 \\
\hline Berpikir Inventif & 70 & 70 & 74 & 76 \\
\hline Produktivitas & 75 & 75 & 78 & 80 \\
\hline Skor Rerata & 76 & 76 & 79 & 82 \\
\hline Predikat & Baik & Baik & Baik & Baik \\
\hline
\end{tabular}

Berdasarkan data dari Tabel 2 di atas, skor rerata studi kasus siswa SMKNJ berada pada kisaran angga 76-82. Sesuai dengan tabel konversi nilai pengetahuan (lihat Tabel 3) yang digunakan di SMKNJ, maka diketahui bahwa hasil pengembangan kompetensi siswa mencapai predikat BAIK.

Tabel 3. Tabel Konversi Nilai Pengetahuan di SMKNJ

\begin{tabular}{|c|c|}
\hline \multicolumn{2}{|c|}{ Pengetahuan } \\
\hline Skor Rerata & Predikat \\
\hline 86 - 100 & Sangat Baik ( A ) \\
\hline $71-85$ & Baik $(B)$ \\
\hline $56-70$ & Cukup ( C ) \\
\hline$\leq 55$ & Kurang (D) \\
\hline
\end{tabular}

Evaluasi pelaksanaan kegiatan pelatihan didasarkan dari kuesioner tentang pelaksanaan kegiatan yang wajib diisi siswa SMKNJ sebagai peserta pelatihan. Dari hasil kuesioner tentang rangkaian kegiatan peningkatan IPTEK, $87 \%$ siswa mengatakan bahwa pelatihan ini SANGAT BERMANFAAT untuk meningkatkan IPTEK mereka. Selanjutnya, dari hasil kuesioner tentang rangkaian kegiatan pengembangan kompetensi, $81 \%$ siswa memilih jawaban SANGAT BERMANFAAT. Selanjutnya, siswa juga diminta untuk menuliskan kesulitan yang dihadapi saat pelaksanaan pelatihan. Sebanyak 89\% siswa menyampaikan merasa kesulitan pada penggunaan Aplikasi Blynk khususnya saat melakukan penyusunan logika dan code sketch pada aplikasi. Siswa juga menyampaikan masukan agar diadakan pelatihan lanjutan yang lebih fokus pada masalah tersebut dengan waktu praktik lebih lama dari waktu pelatihan saat ini agar dapat lebih mendalami penggunaan Aplikasi Blynk.

Sebagai penutup pelaksanaan kegiatan, Tim Pelaksana PKM kembali menemui pihak sekolah untuk memberikan dan menyerahkan laporan pelaksanaan kegiatan yang berisi hasil dan evaluasi serta masukan yang bermanfaat untuk pihak sekolah (lihat Gambar 7). Pada kesempatan ini juga diserahkan Alat Peraga pembelajaran dan file video tutorial agar dapat dipergunakan oleh pihak sekolah untuk pembelajaran selanjutnya. Pada kesempatan ini Tim Pelaksanaan PKM juga memberikan foto kegiatan kepada pihak sekolah sebagai cinderamata dan wujud dari rasa terima kasih kepada mitra 


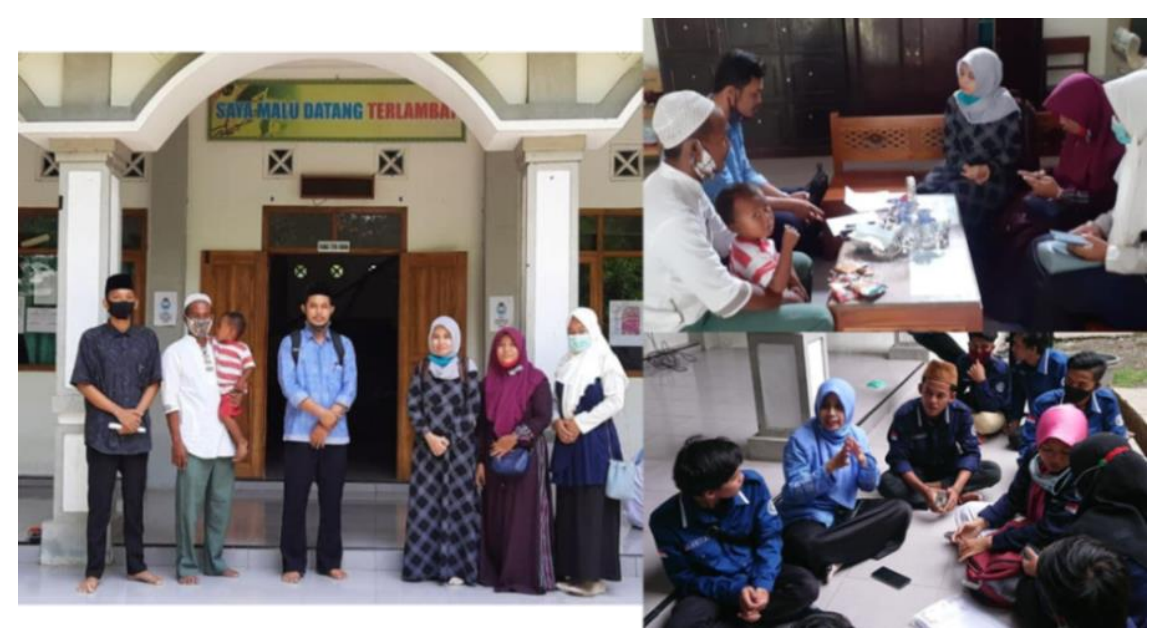

Gambar 6. Foto Kegiatan Penutup dan Evaluasi Bersama Mitra

\section{PENUTUP}

Berdasarkan analisa situasi yang dilakukan oleh Tim Pelaksana PKM dapat disimpulkan terdapat dua permasalahan utama mitra yang memiliki tingkat urgensi tinggi untuk diselesaikan, yaitu peningkatan IPTEK dan pengembangan kompetensi bagi siswa SMKNJ Kelas 12. Oleh sebab itu, kegiatan yang dilakukan melalui pelatihan ini merupakan solusi dari permasalahan tersebut karena dapat menyelesaikan permasalahan internal sekaligus menjadi solusi permasalahan eksternal yang dihadapi mitra.

Dari hasil pengukuran yang dilakukan melalui tes before after, dapat disimpulkan bahwa siswa SMKNJ dapat menerima seluruh materi tentang implementasi IoT dan melakukan praktik dengan baik sehingga terjadi peningkatan IPTEK tentang IoT untuk sistem smart home pada siswa SMKNJ. Demikian juga dengan upaya yang dilakukan untuk pengembangan kompetensi abad 21 melalui kegiatan pembahasan studi kasus. Seluruh kelompok siswa mencapai predikat BAIK.

Kesimpulan untuk seluruh pelaksanaan kegiatan Peningkatan IPTEK Melalui Pelatihan Penerapan Internet of Things (IoT) pada Sistem Smart Home bagi Siswa SMK Nurul Jadid Paiton Probolinggo berlangsung dengan baik. Respons siswa dan pihak sekolah sebagai mitra dapat bekerja sama dengan baik pada kegiatan ini. Dari hasil kuesioner yang disebarkan, siswa SMKNJ merasakan bahwa pelatihan ini sangat bermanfaat bagi peningkatan IPTEK dan juga sangat bermanfaat bagi pengembangan kompetensi abad 21.

Berdasarkan hasil dari kegiatan pelatihan ini, saran yang diajukan oleh Tim Pelaksana PKM dan dapat menjadi acuan untuk kegiatan selanjutnya adalah: 1) Pelaksanaan pelatihan yang fokus pada penggunaan aplikasi IoT untuk sistem smart home. Sebagai contoh yaitu Aplikasi Blynk, 2) Pelaksanaan pengembangan kompetensi abad 21 harus dilakukan secara rutin agar siswa terbentuk menjadi manusia pembelajar dan siap menghadapi tantangan dunia kerja.

\section{UCAPAN TERIMA KASIH}

Kegiatan ini dapat berjalan lancar dan memberikan kontribusi bagi mitra SMK Nurul Jadid Paiton Probolinggo khususnya siswa Kelas 12 karena adanya dukungan dari pihak terkait. Tim Pelaksana PKM mengucapkan terima kasih kepada Universitas Nurul Jadid, dan Bagian LP3M UNUJA, Kepala Sekolah dan jajaran pimpinan SMKNJ sebagai mitra, Mahasiswa Program Studi Teknik Elektro UNUJA (Kelompok KKN 
Kolaborasi Amalia Herlina, S.IIP., M.MT) dan semua pihak yang telah membantu baik secara langsung maupun tidak langsung.

\section{DAFTAR PUSTAKA}

Adi, B., \& Herlina, A. (2019). Smart Home With Smart Control, Berbasis Bluetooth Mikrokontroller. JEECOM: Journal of Electrical Engineering and Computer, 1(1), 1-11. https://ejournal.unuja.ac.id/index.php/jeecom/article/view/883

Afandi, S. (2017). Stimulasi Keterampilan Berpikir Tingkat Tinggi; Konsep dan implementasinya dalam pembelajaran Abad 21. Surakarta: UPT (pp. 58-59). UNS Press.

Junaidi, A. (2015). INTERNET OF THINGS, SEJARAH, TEKNOLOGI DAN PENERAPANNYA : REVIEW. I(3), p.62-66. http://journal.widyatama.ac.id/ index.php/jitter/article/view/66/57

Li, M., Gu, W., Chen, W., He, Y., Wu, Y., \& Zhang, Y. (2018). Smart home: architecture, technologies and systems. Procedia Computer Science, 131, 393-400. 2D9A56D26BF2A7DDAE8A686EE31A0F3DEE079BE8C64A6F8384711335A8 1EAC23032189D69C419E213E335629B12FA87F

Malche, T., \& Maheshwary, P. (2017). Internet of Things (IoT) for building smart home system. 2017 International Conference on I-SMAC (IoT in Social, Mobile, Analytics and Cloud)(I-SMAC), 65-70. https://www.researchgate.net/ profile/Timothy-Malche/publication/313902296_Internet_of_Things_IoT_for_ building_Smart_Home_System/links/5c76932c92851c6950453b18/Internet-ofThings-IoT-for-building-Smart-Home-System.pdf

R. Hafid Hardyanto. (2017). Konsep Internet Of Things Pada Pembelajaran Berbasis Web. Jurnal Dinamika Informatika, 6(1), 87-97.

Sajidan et.al. (2018). Peningkatan Proses Pembelajaran Dan Penilaian Pembelajaran Abad 21 Dalam Meningkatkan Kualitas Pembelajaran SMK. Jakarta: Kemendikbud. Hal 20-21. https://core.ac.uk/download/pdf/227159104.pdf

Setiyani, L. (2019). Perancangan dan Implementasi IoT (Internet of Things) pada Smarthome Menggunakan Raspberry Pi Berbasis Android. Simetris : Jurnal Teknik Mesin, Elektro Dan Ilmu Komputer, 10(2), 459-466. https://jurnal.umk.ac.id/ index.php/simet/article/view/3059/1860

Subani, M., Ramadhan, I., Sumarno, S., \& Putra, A. S. (2021). Perkembangan Internet of Think (IOT) dan Instalasi Komputer Terhadap Perkembangan Kota Pintar di Ibukota Dki Jakarta. IKRA-ITH INFORMATIKA: Jurnal Komputer Dan Informatika, 5(1), 88-93. https://journals.upi-yai.ac.id/index.php/ikraithinformatika/article/view/918/709 